\title{
Research Progress of Cathode Materials for Lithium-ion Batteries
}

\author{
Kaijia Lu' ${ }^{1}$, Chuanshan Zhao ${ }^{1, \mathrm{a}}$ and Yifei Jiang ${ }^{1}$ \\ ${ }^{1}$ State Key Laboratory of Biobased Material and Green Paper making. Qilu University of Technology, Shandong Academy of Sciences, \\ Jinan, shandong 250353, China
}

\begin{abstract}
Lithium-ion batteries have attracted widespread attention as new energy storage materials, and electrode materials, especially cathode materials, are the main factors affecting the electrochemical performance of lithium-ion batteries, and they also determine the cost of preparing lithium-ion batteries. In recent years, there have been a lot of researches on the selection and modification of cathode materials based on lithium-ion batteries to continuously optimize the electrochemical performance of lithium-ion batteries. This article introduces the research progress of cathode materials for lithium ion batteries, including three types of cathode materials (layer oxide, spinel oxide, polyanionic compound) and three modification methods (doping modification, surface coating modification, nano modification method), and prospects for the future development of lithium ion battery cathode materials.
\end{abstract}

\section{Introduction}

The development and application of sustainable development of new energy is a research focus of energy issues $^{[1]}$. Solar energy, tidal energy and wind energy, which are rich in energy storage on the earth, are all green energy sources. However, these green renewable energy sources are plagued by shortcomings such as intermittent, regional and seasonality, and are difficult to effectively use in industrial production and daily life. Lithium-ion battery (LIB) has the advantages of large operating potential, large specific capacity, long cycle life, stable working voltage, and small self-discharge. It is considered to be one of the most promising new generation energy sources in this century ${ }^{[2]}$. In recent years, lithium-ion batteries have played an indispensable role in portable electronic devices, and as electronic products have become necessities in people's daily lives, the demand for lithium-ion batteries has also increased. However, to be implemented in the large-scale high-power system such as the plug-in hybrid electric vehicle (PHEV) or plug-in electric vehicle (PEV), performance requirements are raised especially from the aspects of energy/power density, cycling life and safety issues, therefore further LIB material and system developments are necessary ${ }^{[3]}$.

There are three key components in a lithium-ion battery system: cathode, anode and electrolyte. In lithium-ion batteries, electrical energy is stored in the form of chemical energy, and lithium ions are used as carriers on the cathode and anode to carry out redox reactions. During the charging process, lithium ions are extracted from the positive electrode material, dissolved in the electrolyte, and then transferred to the negative electrode material. At the same time, electrons are transferred from the cathode to the anode through the external current collector, and thus electrical energy is stored. The opposite process occurs during the discharge.

In the development of lithium-ion batteries, the research on new electrode materials has always been the most concerned issue for researchers. In the development process of the past few decades, the improvement of the performance of the anode material is the main reason for the improvement of the capacity performance of the lithium ion battery, the anode material has a specific capacity of more than $300 \mathrm{mAh} \cdot \mathrm{g}^{-1[4]}$. Compared with the negative electrode material, the tap density of the positive electrode material is higher, but only has a low specific capacity of about $200 \mathrm{mAh} \cdot \mathrm{g}^{-1}$, resulting in a slower development of the overall battery performance ${ }^{[5]}$. Therefore, the development of positive electrode materials with the advantages of safety, economy, high performance, and high capacity is particularly important for the development of lithium-ion batteries. Regarding the bottleneck problem that currently hinders the development of cathode materials, researchers have adopted new materials research and development and targeted modification methods to enhance the electrochemical performance of lithium-ion batteries.

This article focuses on summarizing the characteristics and limitations of different cathode materials for lithium-ion batteries, as well as modification methods to improve their performance, and prospects for the future development of cathode materials.

\section{Lithium-ion battery cathode material}

In 1990, Sony successfully prepared lithium-ion batteries for the first time, and launched a rechargeable commercial LiCoO2 ion battery in 1992[6]. With the

$\overline{{ }^{a} \text { Corresponding author: ppzcs78@163.com }}$ 
progress of society, the market demand for lithium-ion batteries is increasing, and the requirements for its performance are also getting higher and higher. In order to optimize the electrochemical performance of lithium-ion batteries, the cathode material of the battery should meet the following requirements[7,8]: (1) Have the lowest possible Fermi level, (2) the diffusion rate of lithium ions should be as fast as possible, (3) have the highest possible potential energy, (4) the conductivity should be as high as possible, (5) It has high structure and chemical stability, (6) easy to prepare and low cost in industrial production.

\subsection{Layered compound $\mathrm{LiMO}_{2}$}

The layered compound LiMO2 cathode material has a layered rock salt phase crystal structure (Fig. 1). Oxygen anions form a densely arranged lattice, and the transition metal cations are located at the octahedral position. The two combine to form a stable MO2 layer, and lithium ions are intercalated between the layers.

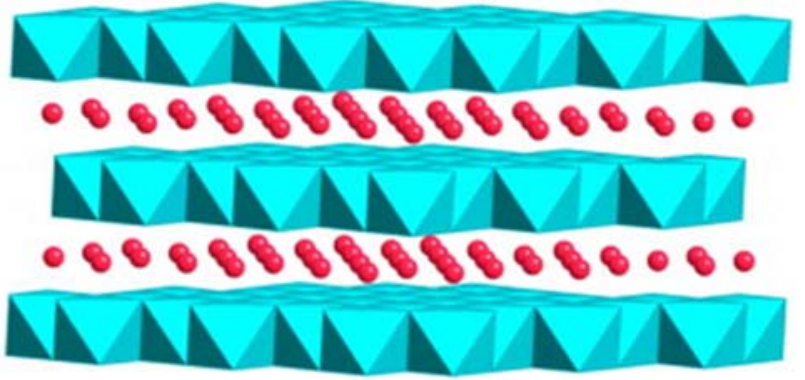

Figure 1. Crystal structure of layered $\mathrm{LiMO}_{2}$ (blue: transition metal ions; red: $\mathrm{Li}$ ions).

$\mathrm{LiCoO}_{2}$ has many different types of crystal forms. In industrial applications, the main crystal form is O3. Its structure is $\alpha-\mathrm{NaFeO}_{2}$ layered structure, which belongs to the hexagonal crystal system and R3m space group ${ }^{[9]}$. As the most studied and most popular cathode material for lithium-ion batteries, $\mathrm{LiCoO}_{2}$ has a theoretical specific capacity of $274 \mathrm{mAh} \cdot \mathrm{g}^{-1}$ and a cycle life of more than 400 cycles. It has relatively stable electrochemical performance at a working voltage of $3.7 \mathrm{~V}$. Although as the longest researched lithium ion battery cathode material, $\mathrm{LiCoO}_{2}$ also has its shortcomings that are difficult to solve, which also limits its further commercial application. First, $\mathrm{LiCoO}_{2}$ can only provide an actual specific capacity of about $140 \mathrm{mAh} \cdot \mathrm{g}^{-1}$, which is only half of its theoretical specific capacity. Secondly, the Co element in the $\mathrm{LiCoO}_{2}$ material is expensive and has a certain degree of toxicity, which not only has a high preparation cost, but also has an adverse effect on the environment. Therefore, in view of these difficult problems, the research on layered compounds turned to $\mathrm{LiCoO}_{2}$ derivatives. By using environmentally friendly and low-cost transition metal ions (such as $\mathrm{Ni}$ and $\mathrm{Mn}$ ) to partially or completely replace $\mathrm{Co}$ ions, the above problems were successfully solved, binary and ternary cathode materials were developed immediately.

Ohzuku $^{[10]}$ et al. first successfully prepared $\mathrm{LiNi}_{0.5} \mathrm{Mnn}_{0.5} \mathrm{O}_{2}$ instead of $\mathrm{LiCoO}_{2}$ as the cathode material of lithium-ion batteries, which has superior electrochemical properties, safety and economy. However, a large amount of immovable Ni hinders the diffusion of $\mathrm{Li}$, resulting in the low rate performance of $\mathrm{LiNi}_{0.5} \mathrm{Mn}_{0.5} \mathrm{O}_{2}$ material. Kang ${ }^{[11]}$ et al. also pointed out this point and improved the rate performance by changing the crystal structure of $\mathrm{LiNi}_{0.5} \mathrm{Mn}_{0.5} \mathrm{O}_{2}$.

In order to overcome the Li-Ni misalignment caused by the presence of a large amount of $\mathrm{Ni}$ in the Li layer, which affects the rate performance of the material. People try to reintroduce $\mathrm{Co}$, hoping to reduce the $\mathrm{Ni}$ content in the Li layer through the presence of Co ions, and create a new compound of $\mathrm{LiCo}_{\mathrm{x}} \mathrm{Ni}_{\mathrm{y}} \mathrm{Mn}_{1-\mathrm{x}-\mathrm{y}} \mathrm{O}_{2}$. Ohzuku ${ }^{[12]}$ et al. prepared $\mathrm{LiCo}_{1 / 3} \mathrm{Ni}_{1 / 3} \mathrm{Mn}_{1 / 3} \mathrm{O}_{2}$ by solid-phase reaction, which can be regarded as a solid solution of $\mathrm{LiCoO}_{2}, \mathrm{LiNiO}_{2}$ and $\mathrm{LiMnO}_{2}$. The reversible capacity and voltage curve of $\mathrm{LiCo}_{1 / 3} \mathrm{Ni}_{1 / 3} \mathrm{Mn}_{1 / 3} \mathrm{O}_{2}$ is similar to that of $\mathrm{LiNi}_{0.5} \mathrm{Mn}_{0.5} \mathrm{O}_{2}$, but due to its complex solid solution mechanism, its working voltage is $0.15 \sim 0.3 \mathrm{~V}$ higher than $\mathrm{LiNi}_{0.5} \mathrm{Mn}_{0.5} \mathrm{O}_{2}$. On this basis, people have turned the research focus to ternary cathode materials with different mass ratios. Studies have shown that the presence of a small amount of Co can improve the electrochemical performance of the material, and then nickel-rich ternary materials including NCM622 and NCM811 occupy the market of commercial cathode materials.

With the in-depth research on layered compound cathode materials, lithium-rich materials have also been found to have certain development prospects as cathode materials. Thackery ${ }^{[13]}$ et al. proposed a lithium-rich solid solution composite oxide system with an actual capacity greater than $200 \quad \mathrm{mAh} \cdot \mathrm{g}^{-1}$ : $\mathrm{xLi}_{2} \mathrm{MnO}_{3} \cdot(1-\mathrm{x}) \mathrm{LiNi}_{1 / 3} \mathrm{Co}_{1 / 3} \mathrm{Mn}_{1 / 3} \mathrm{O}_{2}$. However, due to the detachment of oxygen anions and lithium ions during the charging process, an irreversible initial capacity loss is caused. Therefore, as a further optimization, the material is surface-coated to reduce the irreversible initial capacity loss.

In short, the layered compound $\mathrm{LiMO}_{2}$ can provide high theoretical capacity after being activated by high voltage. However, in practical applications, due to its inherent structural instability and low lithium concentration, the actual reversible capacity is low and the utilization efficiency of active materials is low.

\subsection{Spinel compound $\mathrm{LiM}_{2} \mathrm{O}_{4}$}

The crystal structure of the compound $\mathrm{LiM}_{2} \mathrm{O}_{4}$ is shown in Figure 2. It has a spinel structure and belongs to the Fd3m space group. Oxygen ions occupy the $32 \mathrm{e}$ tetrahedral position in the unit cell, showing that the cubic is closely packed, the transition metal ion (M) is located at the $16 \mathrm{~d}$ octahedral position, and the lithium ions occupy the $8 \mathrm{a}$ tetrahedral position in the Li layer that shares the plane with the hollow octahedral position of the transition metal layer. The voids between the empty tetrahedrons and octahedrons in the transition metal layer provide a three-dimensional channel for the diffusion of lithium ions in the crystal ${ }^{[14,15]}$. 


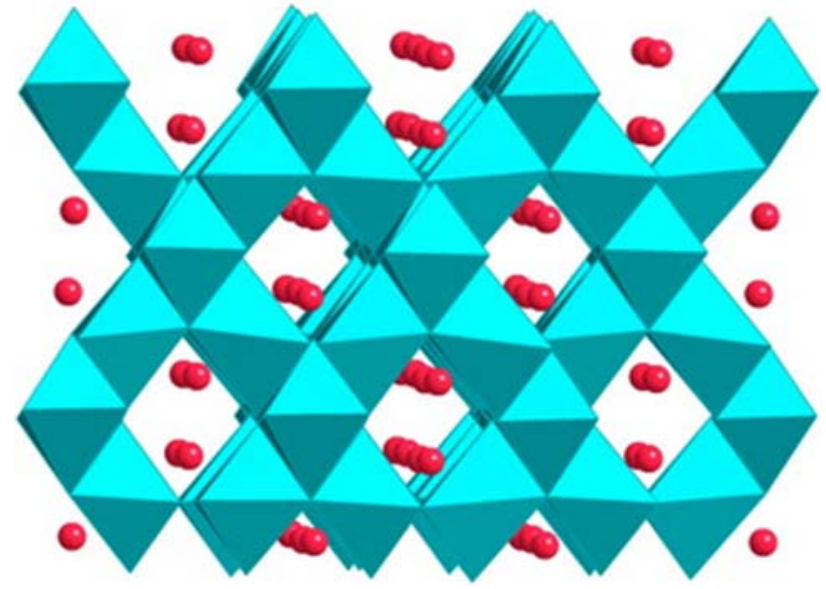

Figure 2. Crystal structure of spinel $\mathrm{LiM}_{2} \mathrm{O}_{4}$ (blue: transition metal ions; red: $\mathrm{Li}$ ions).

The typical representative of spinel-type compound $\mathrm{LiM}_{2} \mathrm{O}_{4}$ cathode material is $\mathrm{LiMn}_{2} \mathrm{O}_{4}$, which has the advantages of high energy density, good cycle performance, superior safety performance and environmental friendliness. However, since the spinel-type compound $\mathrm{LiMn}_{2} \mathrm{O}_{4}$ was proposed as a cathode material for lithium-ion batteries, serious capacity degradation problems have been found ${ }^{[16]}$. When the voltage of $\mathrm{LiMn}_{2} \mathrm{O}_{4}$ material reaches about $3.0 \mathrm{~V}$ during the electrochemical cycle, $\mathrm{Mn}^{3+}$ will induce the John-Teller distortion effect, which causes the spinel structure of the material to change from cubic symmetry to tetragonal symmetry, which reduces the cycle performance of the cathode. And $\mathrm{Mn}^{3+}$ will gradually dissolve in the electrolyte due to the oxidation reaction, resulting in a decrease in specific capacity due to irreversible loss of $\mathrm{Mn}$ element ${ }^{[17]}$. Researchers have found that by improving the structural stability of $\mathrm{LiMn}_{2} \mathrm{O}_{4}$, the problem of poor cycle performance can be effectively overcome. The more commonly used methods include bulk doping and surface coating. $\mathrm{LiNi}_{0.5} \mathrm{Mn}_{1.5} \mathrm{O}_{4}$ shows the best overall electrochemical performance among all doped materials and is considered to be the most likely cathode material to be widely used ${ }^{[18]}$. Oxides and fluorides are mainly used as surface coating materials for $\mathrm{LiMn}_{2} \mathrm{O}_{4}$.

Spinel-type compound materials have become the research hotspot of lithium-ion battery cathode materials in recent years due to their high energy density, three-dimensional lithium ion diffusion channels and good cycle performance after some special modifications. However, the interface side reactions and electrolyte decomposition caused by high voltage will still cause deterioration of the material cycle performance.

\subsection{Polyanionic compound LiMXOn}

\subsubsection{Phosphate compound $\mathrm{LiMPO}_{4}$}

The phosphate compound $\mathrm{LiMPO}_{4}$ has an olivine type, that is, a slightly distorted hexagonal close-packed crystal structure, as shown in Figure 3. Phosphorus ions occupy tetrahedral vacancies in the $\mathrm{LiMPO}_{4}$ lattice, while transition metal ions (M) and lithium ions occupy octahedral vacancies. $\mathrm{MO}_{6}$ octahedron and $\mathrm{PO}_{4}$ tetrahedron constitute the entire crystal framework.

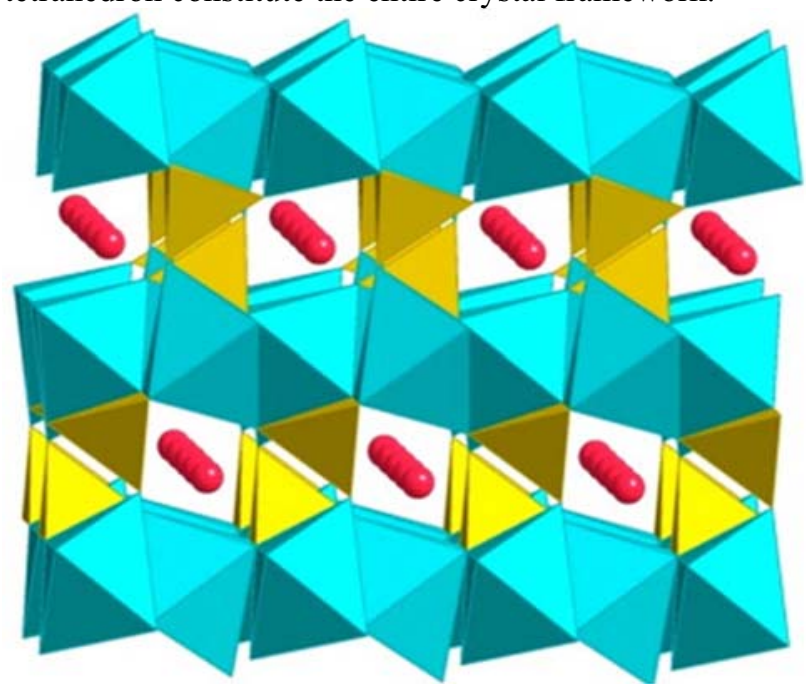

Figure 3. Crystal structure of olivine $\mathrm{LiMPO}_{4}$ (blue: transition metal ions; yellow: P ions; red: Li ions).

Among all olivine-type phosphate compound cathode materials, $\mathrm{LiFePO}_{4}$ is widely used in lithium ion battery cathode materials due to its excellent performance, and is one of the most mature cathode materials. Goodenough ${ }^{[19]}$ et al. first discovered $\mathrm{LiFePO}_{4}$ cathode material. $\mathrm{LiFePO}_{4}$ is low-cost, environmentally friendly, has a theoretical specific capacity of $170 \mathrm{mAh} \cdot \mathrm{g}^{-1}$, and can reach $82.4 \%$ of the theoretical capacity in practical applications, and has a cycle life of more than 1500 times. It is an ideal cathode material. However, $\mathrm{LiFePO}_{4}$ also has its obvious shortcomings. Due to its compact structure, the material crystal lattice is small in stretching and deformation, which makes it difficult to deintercalate lithium ions, making the conductivity of $\mathrm{LiFePO}_{4}$ very low.

Transition metal ions other than Fe (such as Mn, Co, and $\mathrm{Ni}$ ) can also form olivine-type compounds. $\mathrm{LiMPO}_{4} \mathrm{~F}$ is a derivative series of olivine structure, which has many similar properties to $\mathrm{LiMPO}_{4}$. Due to the introduction of fluoride anions, the lithium ion diffusion pathway is changed from one-dimensional to multi-dimensional, which improves the electrical conductivity of the material and has good thermal stability, making it a good substitute for olivine materials.

In short, the olivine-type phosphate compound $\mathrm{LiMPO}_{4}$ has the advantages of low cost, long cycle life and environmental friendliness, and has commercial value for continued research and development. However, low conductivity is still an inherent problem of this series of materials.

\subsubsection{Borate compound $\mathrm{LiMBO}_{3}$}

The borate compound $\mathrm{LiMBO}_{3}$ has the lightest polyanionic group $\mathrm{BO}_{3}$, which can provide a higher theoretical energy density, which has attracted widespread attention. The crystal frame of $\mathrm{LiMBO}_{3}$ is constructed by double pyramids $\mathrm{MO}_{5}$ and triangular $\mathrm{BO}_{3}$ (Fig. 4). The $\mathrm{MO}_{5}$ double pyramid forms a single 
chain and shares edges, the triangular $\mathrm{BO}_{3}$ has a shared angle with the three chains, and lithium ions occupy the shared edges of the two tetrahedrons in the frame.

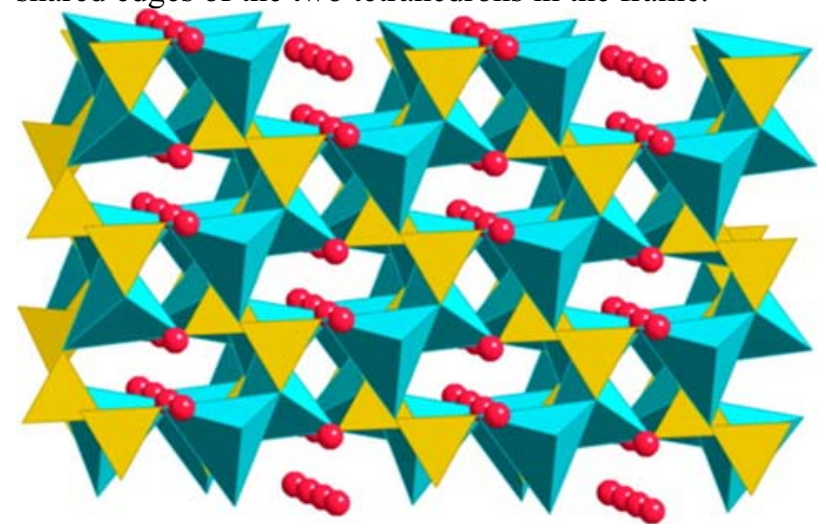

Figure 4. Crystal structure of $\mathrm{LiMBO}_{3}$ (blue: transition metal ions; yellow: B ions; red: $\mathrm{Li}$ ions).

Legagneur ${ }^{[20]}$ et al. first reported $\mathrm{LiMBO}_{3}(\mathrm{M}=\mathrm{Mn}$, $\mathrm{Fe}, \mathrm{Co})$ as a new type of cathode material. From the experimental results, only a very small amount of lithium in these three compounds is reversibly replaced, and the theoretical capacity is as high as $220 \mathrm{mAh} \cdot \mathrm{g}^{-1}$. Dong ${ }^{[21]} \mathrm{et}$ al. successfully synthesized a monoclinic structure of $\mathrm{LiFeBO}_{3}$ cathode material through solid-phase reaction. When the discharge current density is $5 \mathrm{~mA} \cdot \mathrm{g}^{-1}$, an initial discharge capacity of about $125.8 \mathrm{mAh} \cdot \mathrm{g}^{-1}$ can be obtained. And when the discharge current density is increased to $50 \mathrm{~mA} \cdot \mathrm{g}^{-1}$, it can still maintain a specific capacity of $88.6 \mathrm{mAh} \cdot \mathrm{g}^{-1}$ and has excellent cycle stability. Yamada $^{[22]}$ et al. obtained a high reversible capacity of about $190 \mathrm{mAh} \cdot \mathrm{g}^{-1}$ by preparing electrode materials under inert gas argon.

In addition to $\mathrm{LiFeBO}_{3}$, the manganese-based borate $\mathrm{LiMnBO}_{3}$ with hexagonal and monoclinic crystal forms has also been studied. The initial discharge capacity of the hexagonal phase is $75.5 \mathrm{mAh} \cdot \mathrm{g}^{-1}$, except for the first cycle, the average capacity decay is $0.09 \% 0^{[23]}$. The secondary-cycle discharge capacity of monoclinic $\mathrm{LiMnBO}_{3}$ is $100 \mathrm{mAh} \cdot \mathrm{g}^{-1}$, and it has good capacity retention in multiple cycles ${ }^{[24]}$. Borate compound is one of the newer lithium ion battery cathode intercalation materials. Compared with other cathode materials, its performance is relatively poor.

\subsubsection{Silicate compound $\mathrm{Li}_{2} \mathrm{MSiO}_{4}$}

The silicate compound $\mathrm{Li}_{2} \mathrm{MSiO}_{4}$ has an orthogonal structure(Fig. 5). $\mathrm{SiO}_{4}$ tetrahedrons are periodically and repeatedly arranged and form a layered structure with $\mathrm{MO}_{4}$ tetrahedrons. It is worth noting that the $\mathrm{SiO}_{4}$ tetrahedrons are not directly connected together, but share points with the adjacent $\mathrm{MO}_{4}$ tetrahedrons.

Nytén ${ }^{[25]}$ et al. took the lead in studying $\mathrm{Li}_{2} \mathrm{FeSiO}_{4}$ in the silicate compound series as a positive electrode material. $\mathrm{Li}_{2} \mathrm{FeSiO}_{4}$ is synthesized by polymerization reaction and can provide an initial charge capacity of 165 $\mathrm{mAh} \cdot \mathrm{g}^{-1}$ (99\% of the theoretical value), which stabilizes at about $140 \mathrm{mAh} \cdot \mathrm{g}^{-1}(84 \%$ of the theoretical value) after several cycles.

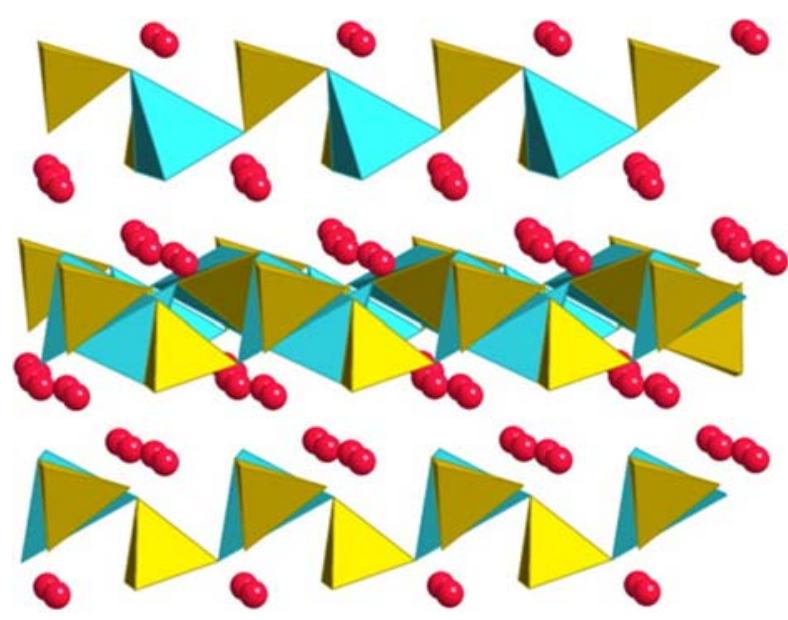

Figure 5. Crystal structure of silicates $\mathrm{Li}_{2} \mathrm{MSiO}_{4}$ (blue: transition metal ions; yellow: Si ions; red: Li ions).

Dominko $^{[26]}$ et al. first successfully synthesized $\mathrm{Li}_{2} \mathrm{MnSiO}_{4}$ through an improved Pechini method. And they proposed that in the crystal structure, $\mathrm{Li}$ and $\mathrm{Mn}$ occupy alternate tetrahedral positions, which further promotes the migration of lithium ions, which means that the ionic conductivity of these materials is very high. $\mathrm{Li}^{[27]}$ et al. synthesized a carbon-coated $\mathrm{Li}_{2} \mathrm{MnSiO}_{4}$ material by solution method precipitation. The reversible capacity at the first charge was $209 \mathrm{mAh} \cdot \mathrm{g}^{-1}$, but the structural instability caused a rapid decrease in capacity.

\section{Modification method of lithium ion battery cathode material}

\subsection{Doping modification}

Doping modification is a method that is widely used to improve the electrochemical performance of lithium ion battery cathode materials. Usually, metal or non-metal ions with a particle size close to the material ions are selected and introduced into the crystal lattice of the cathode material to partially replace the ions in the raw material to achieve the purpose of improving the electrochemical performance of the material.

\subsubsection{Cation doping}

Cation doping belongs to single element doping. By introducing a suitable and appropriate amount of cations to replace some of the lithium ions or transition metal ions in the material, the purpose of improving electrochemical performance is achieved.

For lithium doping, Zhao ${ }^{[28]}$ et al. synthesized $\mathrm{Na}$-doped nickel-rich layered oxide $\mathrm{Li}_{1-\mathrm{x}} \mathrm{Na}_{\mathrm{x}} \mathrm{Ni}_{0.5} \mathrm{Co}_{0.2} \mathrm{Mn}_{0.3} \mathrm{O}_{2} \quad(\mathrm{x}=0.01,0.02,0.03,0.04$, 0.05 ) by a combination of co-precipitation method and high-temperature solid phase method. And compared with the undoped original material $\mathrm{LiNi}_{0.5} \mathrm{Co}_{0.2} \mathrm{Mn}_{0.3} \mathrm{O}_{2}$. The results show that when the $\mathrm{Na}$ doping amount is less than or equal to $2 \%$, the sample has better electrochemical performance and thermal stability than the undoped original material. Since the doped Na ions 
can weaken the $\mathrm{LiO}$ covalent bond, it is conducive to the intercalation and deintercalation of $\mathrm{Li}$ ions in the material. $\mathrm{Li}^{[29]}$ et al. prepared $\mathrm{Na}$-doped $\mathrm{Li}_{\mathrm{x}} \mathrm{Na}_{2-\mathrm{x}} \mathrm{V}_{2} \mathrm{O}_{6}(\mathrm{x}=2,1.4$, $1,0)$ by sol-gel method. Among them, $\mathrm{LiNaV}_{2} \mathrm{O}_{6}(\mathrm{x}=1)$ is the best Na-doped compound, which has a higher capacity at all rates compared with undoped or over-doped samples. This is because $\mathrm{Na}$ doping can provide a good channel and increase the $\mathrm{Li}^{+}$diffusion coefficient of lithium ion insertion and extraction.

For transition metal doping, Eilers-Rethwisch ${ }^{[30]}$ et al. synthesized Sn-doped layered nickel-rich $\mathrm{Li}\left[\mathrm{Ni}_{0.6} \mathrm{Mn}_{0.2} \mathrm{Co}_{0.2-\mathrm{X}} \mathrm{Sn}_{\mathrm{X}}\right] \mathrm{O}_{2}(\mathrm{x}=0-0.05)$ by co-precipitation. The results show that when the doping amount of $\mathrm{Sn}$ is $1 \% \sim 2 \%$, the cycle life of the cathode material is increased by about $20 \%$. Because $\mathrm{Sn}$ doping has a positive effect on reducing the solubility of transition metals and increasing the available lithium content in the active material of the cathode material. Peng ${ }^{[31]}$ et al. successfully prepared Co-doped $\mathrm{LiV}_{1-\mathrm{x}} \mathrm{Co}_{\mathrm{x}} \mathrm{PO}_{4} \mathrm{~F} / \mathrm{C}(\mathrm{x}=0$, $0.01,0.03$ and 0.05 ) by the improved solid phase method. Among them, $\mathrm{LiV}_{0.97} \mathrm{Co}_{0.03} \mathrm{PO}_{4} \mathrm{~F} / \mathrm{C}(\mathrm{x}=0.03)$ has the best electrochemical performance. It has a discharge capacity of $128.3 \mathrm{mAh} \cdot \mathrm{g}^{-1}$ at a rate of $0.5 \mathrm{C}$, and has a capacity retention rate of $96.4 \%$ after 50 cycles at a rate of $3 \mathrm{C}$. This is because a small amount of Co doping not only increases the diffusion coefficient of lithium ions, but also reduces the transfer resistance of lithium ions.

\subsubsection{Anion doping}

Anion doping uses anions with greater electronegativity, such as $\mathrm{F}, \mathrm{Cl}$, or $\mathrm{S}$, to partially replace $\mathrm{O}$ in the material. Among them, $\mathrm{F}$ is the most selected doping element because the doping of $\mathrm{F}$ can form a fluorine-transition metal bond with higher chemical bond energy.

$\mathrm{Li}^{[32]}$ et al. successfully prepared F-doped layered compound material $\mathrm{LiNi}_{0.5} \mathrm{Co}_{0.2} \mathrm{Mn}_{0.3} \mathrm{O}_{1.99} \mathrm{~F}_{0.01}$ by the carbonate co-precipitation method. At a rate of $10 \mathrm{C}$, the sample has an initial discharge capacity of $121 \mathrm{mAh} \cdot \mathrm{g}^{-1}$, and its capacity retention rate is $79.04 \%$ after 500 cycles. $\mathrm{F}$ doping can suppress the side reactions between the electrode and the electrolyte under high pressure, and effectively stabilize the material structure. $\mathrm{Luo}^{[33]}$ et al. synthesized the fluorine gradient doped $\mathrm{LiNi}_{0.5} \mathrm{Mn}_{1.5} \mathrm{O}_{4}$ spinel material by a one-step method. The sample has the best discharge performance at $400^{\circ} \mathrm{C}$, and the discharge capacity is 124.7 and $104 \mathrm{mAh} \cdot \mathrm{g}^{-1}$ at the rate of $1 \mathrm{C}$ and $10 \mathrm{C}$, respectively. Since the doping of fluorine forms a uniform and smooth thin surface on the cathode electrode, the occurrence of side reactions between the cathode and the electrolyte is suppressed, thereby improving the electrochemical performance of the material.

\subsubsection{Anion and cation composite doping}

Anion-cation composite doping belongs to multi-element doping, that is, cations and anions are introduced at the same time, combined with the characteristics of different doping elements, and the positive electrode material is comprehensively modified.

Chen $^{[34]}$ et al. successfully synthesized $\mathrm{Cd}$ and $\mathrm{S}$ co-doped layered lithium-rich manganese-based $\mathrm{Li}_{1.2} \mathrm{Ni}_{0.2} \mathrm{Mn}_{0.6} \mathrm{O}_{2}$ by co-precipitation method. It has an initial discharge capacity of $268.5 \mathrm{mAh} \cdot \mathrm{g}^{-1}$ at a rate of $0.1 \mathrm{C}$, and after 80 cycles, it still has a capacity of 243.4 $\mathrm{mAh} \cdot \mathrm{g}^{-1}$. Due to the simultaneous doping of inactive and large-radius $\mathrm{Cd}$ and $\mathrm{S}$, an inactive large-sized rigid support frame is constructed, which improves the stability of the material. Liu ${ }^{[35]}$ et al. successfully prepared a layered lithium-rich manganese-based $\mathrm{Li}_{1.12} \mathrm{Na}_{0.08} \mathrm{Ni}_{0.2} \mathrm{Mn}_{0.6} \mathrm{O}_{1.95} \mathrm{~F}_{0.05}$ co-doped with $\mathrm{Na}$ and $\mathrm{F}$ by means of ball milling and high-temperature solid-phase reaction. The co-doped sample has good cycle stability. After 100 cycles at a rate of $0.2 \mathrm{C}$, the capacity retention rate is $100 \%$. At the same time, it also has excellent rate performance, with a high rate performance of 167 $\mathrm{mAh} \cdot \mathrm{g}^{-1}$ at a rate of $5 \mathrm{C}$, maintaining the advantages of $\mathrm{Na}$ and $\mathrm{F}$ doping.

\subsection{Surface coating modification}

Surface coating modification is another common and widely used effective method to improve the electrochemical performance of lithium-ion battery cathode materials. There are two main types: one is to coat a layer of stable coating material on the surface of the positive electrode material, and the other is to coat the raw materials with different materials in different layers to form a composite coating layer. The surface coating can effectively prevent the direct contact between the active material of the positive electrode material and the electrolyte, avoid the dissolution of the transition metal due to the occurrence of side reactions, and maintain the structural stability of the positive electrode material during the cycle. Surface coating can also increase the electrical conductivity of the material and enhance the mobility of $\mathrm{Li}^{+[36]}$.

Yang $^{[37]}$ et al. synthesized the original sample $\mathrm{Li}\left[\mathrm{Li}_{0.2} \mathrm{Mn}_{0.54} \mathrm{Ni}_{0.13} \mathrm{Co}_{0.13}\right] \mathrm{O}_{2}$ by high-temperature solid-phase reaction. The nano-sized $\mathrm{Li}_{4} \mathrm{~V}_{2} \mathrm{Mn}\left(\mathrm{PO}_{4}\right)_{4}$ coating was prepared by the sol-gel method combined with freeze-drying, and finally the nano-particle coating material was coated on the original sample through electrostatic interaction under the condition of ball mill rotation. The original material coated with $\mathrm{Li}_{4} \mathrm{~V}_{2} \mathrm{Mn}\left(\mathrm{PO}_{4}\right)_{4}$ shows excellent electrochemical performance. The initial Coulombic efficiency is as high as $84.2 \%$, and the capacity retention rate is $82 \%$ after 50 cycles at a rate of $0.2 \mathrm{C}$, showing good cycle stability. Due to the existence of the nano-sized $\mathrm{Li}_{4} \mathrm{~V}_{2} \mathrm{Mn}\left(\mathrm{PO}_{4}\right)_{4}$ coating, the original material is isolated from the air, thereby inhibiting the reaction of residual lithium compounds on the surface of the material with moisture and carbon dioxide in the air.

Zheng ${ }^{[38]}$ et al. successfully prepared $\mathrm{LiNi}_{0.8} \mathrm{Co}_{0.15} \mathrm{Al}_{0.05} \mathrm{O}_{2}$ coated with $\mathrm{Li}_{4} \mathrm{SiO}_{4}$ through a combination of wet chemistry and solid phase method. The coated modified sample showed a discharge capacity of $156.5 \mathrm{mAh} \cdot \mathrm{g}^{-1}$ at a rate of $10 \mathrm{C}$, and the capacity retention rate was $88 \%$ after 100 cycles at a rate of $1 \mathrm{C}$. Compared with the original sample, the electrochemical performance has been greatly improved. Due to the high 
calcination temperature, the $\mathrm{Li}_{4} \mathrm{SiO}_{4}$ coating is tightly coated on the LNCA material. The two are firmly combined to increase the stability of the structure. At the same time, it protects the active material in the main material to avoid direct contact with the electrolyte and cause side reactions.

$\mathrm{Liu}^{[39]}$ et al. synthesized a complex $\mathrm{In}_{2} \mathrm{O}_{3} \& \mathrm{LiInO}_{2}$ co-coating on the surface of $\mathrm{LiNi}_{0.8} \mathrm{Co}_{0.1} \mathrm{Mn}_{0.1} \mathrm{O}_{2}$ by wet coating method. At the same time, $\operatorname{In}_{2} \mathrm{O}_{3}$ reacts with the remaining lithium compounds $\mathrm{Li}_{2} \mathrm{CO}_{3}$ and $\mathrm{LiOH}$ on the surface of the original sample to form $\mathrm{LiInO}_{2}$, the remaining lithium compound on the surface of the original sample is consumed, and a firm bond is formed with the $\mathrm{In}_{2} \mathrm{O}_{3}$ coating. The $\mathrm{LiNi}_{0.8} \mathrm{Co}_{0.1} \mathrm{Mn}_{0.1} \mathrm{O}_{2}$ material with a composite coating layer exhibits excellent cycle stability at a rate of $1 \mathrm{C}$, with a capacity retention rate of about 90\%. Moreover, it also showed a discharge capacity of $177.1 \mathrm{mAh} \cdot \mathrm{g}^{-1}$ at a high rate of $5 \mathrm{C}$, and the capacity retention rate was $86.4 \%$ after 300 cycles.

\subsection{Nano modification method}

In addition to the two more common modification methods mentioned above, the development of nanotechnology has provided new means for the modification of cathode materials. First, the cathode material is coated with carbon-based materials, and then nanocomposite materials are synthesized. The nano-modification method makes the composite material have the advantages of high reversibility capacity, good cycle stability and high rate performance at the same time.

Ragupathi ${ }^{[40]}$ et al. successfully prepared nano-pyramid $\mathrm{LiMnPO}_{4} / \mathrm{C}$ materials by polymer precursor method. At a rate of $0.1 \mathrm{C}$, the first discharge capacity of the material is $164.2 \mathrm{mAh} \cdot \mathrm{g}^{-1}$, and it still maintains a capacity of $130.8 \mathrm{mAh} \cdot \mathrm{g}^{-1}$ after 500 cycles. It has a high capacity retention rate of $79.75 \%$. Due to the existence of conductive carbon coating, materials with poor conductivity have been greatly improved, and the existence of nano-pyramid morphology provides more active sites and promotes the migration of lithium ions in the process of intercalation and deintercalation.

Lei ${ }^{[41]}$ et al. prepared $\mathrm{LiMn}_{0.85} \mathrm{Fe}_{0.15} \mathrm{PO}_{4} / \mathrm{C}$ with nano/micro hierarchical structure by solvothermal synthesis method combined with spray pyrolysis method. The material has a reversible discharge capacity of 171.2 $\mathrm{mAh} \cdot \mathrm{g}^{-1}$ at a rate of $0.1 \mathrm{C}$, which is almost equal to its theoretical capacity. And at the rate of $0.1 \mathrm{C}$ and $1 \mathrm{C}$, the capacity retention rate after 100 cycles is $93 \%$ and $90 \%$, respectively. The excellent electrochemical energy is derived from the special hierarchical structure of the nano-primary particles. The nano-particles are assembled into secondary microspheres with many nanopores. This type of nano/micro structure can effectively increase the specific surface area and facilitate the penetration of electrolytes.

Zhang $^{[42]}$ et al. used an improved spray drying method to prepare carbon-coated $\mathrm{LiMn}_{0.8} \mathrm{Fe}_{0.2} \mathrm{PO}_{4}$ nanoporous microspheres. The material has a discharge capacity of $140 \mathrm{mAh} \cdot \mathrm{g}^{-1}$ and $110 \mathrm{mAh} \cdot \mathrm{g}^{-1}$ at a rate of 0.2
$\mathrm{C}$ and $10 \mathrm{C}$, respectively. And at the rate of $0.2 \mathrm{C}$ and $1 \mathrm{C}$, after 200 cycles and 100 cycles, the capacity retention rates are $90.2 \%$ and $95 \%$, respectively. Nanoporous microspheres with high porosity have a short lithium ion diffusion distance, which promotes the migration of lithium ions in the material.

\section{Conclusion}

In the development of lithium-ion batteries, cathode materials are the hotspot and focus of research, not only because of the large development space of cathode materials and the key influence on the electrochemical performance of lithium-ion batteries, but also because the cathode material determines the cost of preparing lithium-ion batteries. This article reviews and summarizes the characteristics and limitations of different cathode materials for lithium-ion batteries, and introduces the latest research progress of corresponding modification methods in detail.

Lithium-ion batteries have been widely used in various portable electronic devices and are the most in demand batteries in the secondary battery market. As the consumer market shifts from portable electronic devices to new energy vehicles, the cost, safety, energy density, and cycle life of lithium-ion batteries are still the focus of research. The development of cathode materials with low cost, high energy density and stable structure, as well as the exploration of more efficient modification methods will be an important research direction of lithium ion battery cathode materials.

\section{References}

1. W.B.Liang, S.Y.Li, X.L.Cui. Bulletin of the Chinese Ceramic Society, 38,11(2019).

2. L.S.Zhang, H.Wang, L.Z.Wang. Mater. Lett, 185, 100 103(2016).

3. B.Xu, D.N.Qian, Z.Y.Wang, Mater. Sci. Eng., R, 73, 5 6(2012).

4. X.Y.Cai, L.F.Lai, Z.X.Shen. J. Mater. Chem. A, 5, 30(2017).

5. D.D.Lecce, R.Verrelli, J.Hassoun. Green Chem, 19, 5(2017).

6. X.J.Huang. Materials China, 29,8(2010).

7. R.Koksbang, J.Barker, H.Shi. Solid State Ionics, 84, 1 2(1996).

8. Y.J.Liu, Y.Y.Gao, A.C.Dou. J. Power Sources, 248, 679 684(2014).

9. X.J.Zhai, Y.G.Zhou, Y.Fu. J. Rare Earths, 23, 2(2005).

10. T.Ohzuku, Y.Makimura. Chem. Lett, 30,8(2001).

11. K.Kang, Y.S.Meng, J.Bréger. Science, 311, 5763 (2006).

12. T.Ohzuku, Y.Makimura. Chem. Lett, 1,7(2001).

13. M.M.Thackeray, S.H.Kang, C.S.Johnson. J. Mater. Chem, 17,30(2007). 
14. A.V.Potapenko, S.A.Kirillov. J. Energy Chem, 23, 5(2014).

15. K.Hoang. J. Mater. Chem. A, 2,43(2014).

16. M.M.Thackeray, P.G.Bruce, J.B.Goodenough. Mater. Res. Bull, 18,4(1983).

17. H.W.Lee, P.Muralidharan, R.Ruffo. Nano Lett, 10,10(2010).

18. J.W.Fergus. J. Power Sources, 195,4(2010).

19. A.Padhi, K.S.Nanjundaswamy, J.B.Goodenough. J. Electrochem. Soc, 144,4(1997).

20. V.Legagneur, Y.An, A.Mosbah. Solid State Ionics, 139,1 2(2001).

21. Y.Z.Dong, Y.M.Zhao, Z.D.Shi. Electrochim. Acta, 53,5(2008).

22. A.Yamada, N.Lwane, Y.Harada. Adv. Mater, 22,32(2010).

23. L.Chen, Y.M.Zhao, X.N.An. J. Alloys Compd, 494,1 2(2010).

24. J.C.Kim, C.J.Moore, B.Kang, J. Electrochem. Soc, 158,3(2011).

25. A.Nytén, A.Abouimrane, M.Armand. Electrochem. Commun, 7,2(2005).

26. R.Dominko, M.Bele, M.aberšček. Electrochem. Commun, 8,2(2006).

27. Y.X.Li, Z.L.Gong, Y.Yang. J. Power Sources, 174,2(2007).

28. R.R.Zhao, Z.L.Yang, J.X.Liang. J. Alloys Compd, 689,318 325(2016).

29. K.Q.Li, L.F.Cao, Z.Huang. J. Power Sources, 344,15(2017).

30. M.E.Rethwisch, S.Hildebrand M.Evertz. J. Power Sources, 397,1(2018).

31. Z.D.Peng, Z.G.Gan, K.Du. J. Alloys Compd, 730, $5(2018)$.

32. L.S.Li Z.Zhang, S.H.Fu. Appl. Surf. Sci, 476,15(2019).

33. Y.Luo, H.Y.Li, T.L.Lu. Electrochim. Acta, 238,1(2017).

34. G.R.Chen, J.An, Y.M.Meng. Nano Energy, 57,157 165(2019).

35. D.M.Liu, X.J.Fan, Z.H.Li. Nano Energy, 58,786 796(2019).

36. P.Y.Guan, L.Zhou, Z.L.Yu. J. Energy Chem, 43,220 235(2020).

37. S.Q.Yang, P.B.Wang, H.X.Wei. Nano Energy, 63,103889(2019).

38. J.C.Zheng, Z.Yang, Z.J.He. Nano Energy, 53,613 621(2018).

39. Y.Liu, L.B.Tang, H.X.Wei. Nano Energy, 65,140043(2019).

40. V.Ragupathi, P.Panigrahi, G.S.Nagarajan. Appl. Surf. Sci, 495,143541(2019).

41. Z.H.Lei, J.L.Wang, J.Yang. ACS Appl. Mater. Interfaces, 10,43552 43560(2018).
42. X.Zhang, M.Y.Hou, A.G.Tamirate. J. Power Sources, $448,227438(2020)$. 